\title{
Azoarcus Grass Endophytes Contribute Fixed Nitrogen to the Plant in an Unculturable State
}

\author{
Thomas Hurek, ${ }^{1,2}$ Linda L. Handley, ${ }^{3}$ Barbara Reinhold-Hurek, ${ }^{4}$ and Yves Piché ${ }^{1}$ \\ ${ }^{1}$ Centre de recherche en biologie forestière, Pavillon C.-E.-Marchand, Université Laval, Québec, Canada G1K-7P4; ${ }^{2}$ Max \\ Planck Institut für terrestrische Mikrobiologie, Arbeitsgruppe Symbiose, Karl von Frisch Str., D-35043 Marburg, Germany; \\ ${ }^{3}$ Scottish Crop Research Institute, Invergowrie, Dundee DD2 5DA, Scotland, U.K.; ${ }^{4}$ University of Bremen, FB 2, Laboratory \\ for General Microbiology, PO. Box 3304 40, D-28334 Bremen, Germany
}

Submitted 20 August 2001. Accepted 11 November 2001.

The extent to which the $\mathrm{N}_{2}$-fixing bacterial endophyte Azoarcus sp. strain BH72 in the rhizosphere of Kallar grass can provide fixed nitrogen to the plant was assessed by evaluating inoculated plants grown in the greenhouse and uninoculated plants taken from the natural environment. The inoculum consisted of either wild-type bacteria or nifK $K^{-}$mutant strain BHNKD4. In $\mathrm{N}_{2}$-deficient conditions, plants inoculated with strain BH72 $\left(\mathbf{N}_{2}\right.$-fixing test plants) grew better and accumulated more nitrogen with a lower $\delta^{15} \mathrm{~N}$ signature after 8 months than did plants inoculated with the mutant strain (non- $\mathrm{N}_{2}$-fixing control plants). Polyadenylated or polymerase chain reaction-amplified BH72 nifH transcripts were retrieved from test but not from control plants. BH72 nifH transcripts were abundant. The inocula could not be reisolated. These results indicate that Azoarcus sp. BH72 can contribute combined $\mathrm{N}_{2}$ to the plant in an unculturable state. Abundant BH72 nifH transcripts were detected also in uninoculated plants taken from the natural environment, from which Azoarcus sp. BH72 also could not be isolated. Quantification of nitrogenase gene transcription indicated a high potential of strain BH72 for biological $\mathrm{N}_{2}$ fixation in association with roots. Phylogenetic analysis of nitrogenase sequences predicted that uncultured grass endophytes including Azoarcus spp. are ecologically dominant and play an important role in $\mathrm{N}_{2}$-fixation in natural grass ecosystems.

The extent to which potentially nitrogen-fixing bacteria in the rhizosphere of gramineous plants are functional in providing combined $\mathrm{N}_{2}$ to the plant is a long-standing question (Boddey et al. 1995; Bormann et al. 1980; van Berkum and Bohlool 1980). For several uninoculated, soilgrown Gramineae spp., ${ }^{15} \mathrm{~N}$-enriched tracer studies have shown that microbial communities can fix substantial amounts of atmospheric $\mathrm{N}_{2}$ from which the plants profit significantly (Boddey et al. 1995; Giller and Day 1985). It was estimated that up to $70 \%$ of plant nitrogen originates from biological nitrogen fixation for certain Brazilian sugar cane cultivars (Boddey 1995; Urquiaga et al. 1992) or $20 \%$ for certain Asian rice varieties (Boddey et al. 1995; Shrestha and Ladha 1996). Identifying the diazotrophic bacteria responsible for the $\mathrm{N}$-gain is important for ag-

Corresponding author: T. Hurek, Telephone: 0049-0421-2182001/2370; Fax: 0049-0421-2184042; E-mail: thurek@ uni-bremen.de

Current address of T. Hurek: University of Bremen, FB 2, Corporation lab Max-Planck-Institute for Marine Microbiology, PO. Box 3304 40, D 28334 Bremen, Germany. ricultural applications as well as for understanding ecosystem processes (Bormann et al. 1980; Reinhold-Hurek and Hurek 1998) because nitrogen is one of the most important limiting nutrients for ecosystem production. However, most of the studies attempting to identify the functionally active diazotrophs are based on classical isolation techniques; although for most ecosystems, it is known that the majority of the bacteria cannot be cultivated yet (Pace 1997). Because of a tight association with the plant, it has been suggested that nitrogen-fixing grass endophytes contribute nitrogen to the plant (Boddey et al. 1995; James and Olivares 1998; Reinhold-Hurek and Hurek 1998).

Grass endophytes are non-nodule-forming, nonleguminous microorganisms that spend most of their life cycle inside plant tissues without causing symptoms of plant damage. Diazotrophic grass endophytes, such as Azoarcus, Herbaspirillum, and Acetobacter spp., differ markedly from other plant-colonizing bacteria such as Rhizobium or Azospirillum in that they do not survive well in and often cannot be isolated from root-free soil (James and Olivares 1998; Reinhold-Hurek and Hurek 1998). However, it is not known which bacteria are responsible for that fixation in all cases investigated so far, except for one recent study on Acetobacter diazotrophicus associated with sugar cane (Sevilla et al. 2001).

In addition, Azoarcus sp. strain BH72 is likely to be a functionally active grass endophyte. In Kallar grass (Leptochloa fusca (L.) Kunth), which yields two to four hay harvests per year without application of nitrogen fertilizer on low-fertility, often flooded soil in Pakistan (Reinhold-Hurek et al. 1993b), it was found to be the predominant endophytic isolate from roots (Reinhold et al. 1986). In situ hybridization experiments demonstrated that Azoarcus sp. nitrogenase genes are expressed in the aerenchyma of field-grown Kallar grass roots (Hurek et al. 1997a). Light and electron microscopic studies revealed that strain $\mathrm{BH} 72$ is also able to infect rice seedlings and promote their growth, although there was no evidence for a contribution of fixed nitrogen in this gnotobiotic system (Hurek et al. 1994). In a different gnotobiotic culture system, Azoarcus sp. strain BH72 shows high levels of nitrogenase gene expression inside roots of rice seedlings as demonstrated by reporter gene studies using transcriptional fusions between the genes encoding the iron protein of nitrogenase (nifH) and the green fluorescent protein $(g f p)$ or $\beta$-glucuronidase $(g u s)$ (Egener et al. 1998, 1999). However, these experiments did not prove whether Azoarcus sp. strain BH72 is capable of contributing significant amounts of fixed nitrogen to a host plant and is the predominantly active $\mathrm{N}_{2}$-fixing endophyte in its host plant in situ. 
Azoarcus sp. BH72 (Hurek et al. 1994) and other diazotrophs such as Azospirillum spp. (Okon and LabanderaGonzalez 1994) can stimulate plant growth by mechanisms other than nitrogen fixation; therefore, we used a nif mutant as a control inoculum to evaluate the amount of fixed nitrogen contributed to the plant by the wild type bacterium. To identify the most active diazotrophic bacterium (in inoculated or uninoculated, in situ-grown plants), we developed molecular, culture-independent methods. For this purpose, culturing techniques have been widely used, but these techniques may lead to misinterpretations of the composition of the active population of diazotrophs and cause biased results due to cultivation techniques. Furthermore, widely used molecular techniques of nif DNA retrieval from the natural environment (Lovell et al. 2000; Ohkuma and Kudo 1996; Ueda et al. 1995) only show the mere presence of nitrogenase genes or the diversity of diazotrophs. However, only studies on nif-mRNA expression can evaluate the actual activity of a particular microbe within a pool of other diazotrophs in an uninoculated natural system. This applies also for inoculation experiments where plants might be contaminated by other diazotrophs, raising the question of who is responsible for the observed nitrogen contribution.

Expression of nitrogenase genes at the time of sampling can be detected by reverse transcription-polymerase chain reaction (RT-PCR). In Azoarcus sp. BH72 (Egener et al. 1998, 1999), as also in many other diazotrophs (Merrick and Edwards 1995), there is a tight relationship between nitrogenase activity and nifH transcription. In the presence of combined nitrogen or unfavorable oxygen concentrations for nitrogen fixation, nitrogenase expression also is repressed. One possible discrepancy is the rapid inactivation of nitrogenase activity upon addition of ammonium, leading to an immediate cessation in nitrogen fixation while mRNA is still present (Egener et al. 2001). However, in the equilibrium situations in the natural environment, rates of transcription will have been adjusted accordingly. Moreover, in bacteria, mRNAs underlie a rapid turnover. Therefore, RT-PCR followed by comparative sequence analysis of nifH mRNAs are methods of choice for quantification of nitrogen fixation as well as identification and evaluation of nitrogen-fixing bacteria in situ. These techniques have been used recently to detect mRNA of several genes, including nifH, in the natural environment (Kowalchuk et al.

Table 1. Growth parameters of Kallar grass plants inoculated with Azoarcus sp. BH72

\begin{tabular}{|c|c|c|}
\hline Parameter & nifk $^{-}$Mutant $^{\mathrm{a}}$ & Wild type $^{\mathrm{a}}$ \\
\hline \multicolumn{3}{|c|}{ Dry weight (g) } \\
\hline Plant & $0.61(0.08)^{b}$ & $1.02(0.13)$ \\
\hline Shoot & $0.37(0.03)^{b}$ & $0.62(0.08)$ \\
\hline Root & $0.24(0.08)^{c}$ & $0.40(0.08)$ \\
\hline \multicolumn{3}{|c|}{ Total nitrogen (mg) } \\
\hline Plant & $2.8(0.4)^{\mathrm{b}}$ & $4.2(0.5)$ \\
\hline Shoot & $1.5(0.4)^{\mathrm{c}}$ & $2.4(0.04)$ \\
\hline Root & $1.2(0.2)$ & $1.9(0.5)$ \\
\hline Soil & $1.7(0.2)^{\mathrm{d}}$ & $1.6(0.2)^{\mathrm{d}}$ \\
\hline \multicolumn{3}{|l|}{$\delta^{15} \mathrm{~N}(\%)$} \\
\hline Plant & $+0.2(0.5)^{\mathrm{b}}$ & $-3.2(0.9)$ \\
\hline Shoot & $-3.1(0.3)$ & $-4.2(0.9)$ \\
\hline Root & $+4.1(0.8)^{\mathrm{b}}$ & $-2.5(1.3)$ \\
\hline Soil & n. d. ${ }^{\mathrm{e}}$ & $-0.68(0.1)$ \\
\hline \multicolumn{3}{|c|}{$\begin{array}{l}\text { a Values are means of } \mathrm{n}=4 \text { with } 4 \text { to } 6 \text { plants each, standard deviations } \\
\text { given in parenthesis. } \\
\text { b Treatments were different at } \mathrm{P}<0.005 \text {. } \\
\text { c Treatments were different at } \mathrm{P}<0.05 \text {. } \\
{ }^{\mathrm{d}} \text { Per compartment. Before planting, soil contained } 2(0.3) \mathrm{mg} \text { total } \\
\text { nitrogen per compartment and had a } \delta^{15} \mathrm{~N} \text { of }-0.63(0.02) ; \mathrm{n}=3 \text {. } \\
\text { e }\end{array}$} \\
\hline
\end{tabular}

1999; Noda et al. 1999; Zani et al. 2000) and have been adopted by us to study root-associated nitrogen fixation.

Here we show by three independent lines of evidence (two molecular and one isotopic) that inoculated plants benefit from $\mathrm{N}_{2}$-fixation by Azoarcus sp. BH72, and provide evidence that other bacteria, including Azoarcus spp., may be functionally similar. We also show that nifH (encoding the iron protein of nitrogenase) of Azoarcus sp. strain BH72 is abundantly expressed in the rhizosphere of naturally grown and inoculated Kallar grass, although this bacterium could not be cultured anymore. Unprecedentedly so far in nonleguminous plant ecosystems, one defined bacterium proved to provide fixed nitrogen to the plant in an unculturable state.

\section{RESULTS}

\section{Plant response to inoculation.}

Kallar grass seedlings pregrown on a substrate containing combined nitrogen were transferred to an inoculated, nitrogenpoor substrate without further $\mathrm{N}$ fertilization. The inoculum consisted of either wild-type Azoarcus sp. BH72 (for $\mathrm{N}_{2}$-fixing test plants) or of the isogenic nifK $K^{-}$mutant strain BHNKD4 (non- $\mathrm{N}_{2}$-fixing control plants). Final dry weight, total nitrogen content, and $\delta^{15} \mathrm{~N}$ of plants were determined in four separate experiments. Plants inoculated with wild-type bacteria had significantly higher dry weights, lower $\delta^{15} \mathrm{~N}$, and $1.4 \mathrm{mg}$ more nitrogen than did plants inoculated with strain BHNKD4 (Table 1). Our N-balance indicated that this difference in plant nitrogen was not originating from $\mathrm{N}$-uptake from the potting medium. Over the 8 months, plants were not fertilized with combined nitrogen. The total soil $\mathrm{N}$ in the compartment decreased equally in both treatments; however, by only 0.4 to $0.3 \mathrm{mg}$ of N (Table 1).

In addition, our isotopic data indicated that the soil was not a major source of the observed nitrogen gain (Table 1). The ratio between the natural isotopes ${ }^{15} \mathrm{~N}$ and ${ }^{14} \mathrm{~N}\left(\delta^{15} \mathrm{~N}\right.$ signature $)$, which can be determined by a high-resolution mass spectrometer, is characteristic of the nitrogen source used in a system. Generally, nitrogenase discriminates the heavier isotope, leading to a decreased abundance of ${ }^{15} \mathrm{~N}$ when $\mathrm{N}_{2}$ is the source of nitrogen (Hoering and Ford 1960). The $\delta^{15} \mathrm{~N}$ signature of the whole plant thus reflects the $\delta^{15} \mathrm{~N}$ signature of the immediate nitrogen source. The $\delta^{15} \mathrm{~N}$ signature of the plants which showed the nitrogen gain (plants inoculated with the wild type) was significantly different from the $\delta^{15} \mathrm{~N}$ signature of the potting medium (Table 1); therefore, these plants must have had access to nitrogen sources other than potting medium. Moreover, the difference in the $\delta^{15} \mathrm{~N}$ signature of these plants compared with the control plants indicated that the plants in both treatments had access to different nitrogen sources. A strong decrease in natural ${ }^{15} \mathrm{~N}$ abundance (wild-type inoculum, $-3.2 \%$; nifK $K^{-}$inoculum, $+0.2 \%$ ) indicated a contribution of fixed nitrogen in the plant inoculated with the wild-type Azoarcus sp. We also determined the ${ }^{15} \mathrm{~N}$-discrimination in pure cultures of strain $\mathrm{BH} 72$ when grown on $\mathrm{N}_{2}$. A similarly negative signature $\left(\delta^{15} \mathrm{~N},-3.9 \%\right.$ ) as in free-living cultures of Anabaena (-3.8\%o) or Azotobacter (-4.4\%o) (Rowell et al. 1998) was detected, corroborating the fact that the plant nitrogen gain had to be attributed to $\mathrm{N}_{2}$ fixation. The slight deviation of the $\delta^{15} \mathrm{~N}$ signature of the control plants compared with the N-poor potting medium originates from the pregrowth of the seedlings in a different substrate.

\section{Reisolation of the inoculum.}

Koch's postulates provide criteria to determine whether a certain bacterium is the agent causing a certain disease. One of these criteria is to reisolate a bacterium from a patient showing 
the symptoms after he had been infected with this bacterium. In analogy, the bacterium causing the nitrogen gain of a plant after inoculation should be reisolated from these plants. Therefore, we attempted to reisolate a Azoarcus sp. 3 months after inoculation and at harvest, using established protocols which had led to enrichment and isolation of Azoarcus spp. originally (Reinhold et al. 1986; Reinhold-Hurek et al. 1993b). All attempts to do so failed; cells with morphology or 16S rDNA sequences (Hurek et al. 1993) typical of strain BH72 could not be enriched from dilutions of macerated roots or root pieces or the shoot. The presence of strain BH72 in roots and shoots also was investigated by $16 \mathrm{~S}$ rDNA-directed PCR. Total DNA extracted from roots at the time of harvesting was subjected to PCR with primers TH14/TH2 followed by oligonucleotide hybridization which specifically detects Azoarcus spp. (Hurek et al. 1993). Hybridization of amplification products was obtained from plants inoculated with both wild-type or nifK Azoarcus (not shown), showing that both Azoarcus strains were present in roots, albeit the signal obtained from the nifK mutant was weaker. Thus, both strains were present but probably not culturable. No amplification product was obtained from shoot preparations, indicating that either the Azoarcus sp. did not colonize the shoot or colonization was below the detection level (data not shown).

\section{Analysis of root-associated nifH mRNA by polyadenylation- and nifH-specific RT-PCR from inoculated plants.}

Molecular ecological methods were developed in order to retrieve and analyze bacterial nitrogenase gene (nifH) mRNA from plant roots. We used (i) screening of a cDNA library and (ii) nifH-specific RT-PCR to show that Azoarcus sp. BH72 was expressing nitrogenase genes. Surprisingly, in Azoarcus sp. BH72, mRNA was polyadenylated as shown with a digoxigenin-labeled poly (dT) oligonucleotide as a probe in Northern blot hybridization experiments (Fig. 1A). The polyadenylated mRNA appeared as a smear from $2 \mathrm{~kb}$ down with its greatest intensity $<1 \mathrm{~kb}$, suggesting that polyadenylation in this bacterium occurs after posttranscriptional processing or degradation of polycistronic mRNA with a high fraction of polyadenylated degraded mRNA molecules. To detect mRNAs nonselectively, we screened a library which was synthesized on poly $(\mathrm{A})^{+}$ RNA isolated from roots of inoculated Kallar grass at harvest. Among 20,000 colonies, one nifH cDNA clone was detected. It carried a truncated nifH cDNA identical to the Azoarcus sp. $\mathrm{BH} 72$ nifH gene that was polyadenylated within the coding region (Fig. 1B). The 85-nt-long poly(A) tract was interspersed with other nucleotides as in polyadenylation of $\mathrm{T} 7 \mathrm{mRNAs}$ (Johnson et al. 1998) or chloroplast pbsA mRNAs (Lisitsky et al. 1996). The retrieval of this clone, albeit truncated, showed that Azoarcus sp. BH72 was metabolically active and expressed nitrogenase genes in roots of inoculated Kallar grass.

This conclusion was supported by RT-PCR with universal primers for the nifH gene, which was carried out on total RNA extracted from roots 3 and 8 months after inoculation. RT-PCR amplification resulted in DNA fragments which hybridized with a nifH probe from strain BH72 (Fig 2A), whereas a nontemplate control in which reverse transcriptase was inactivated was negative (Fig. 2A). Sequencing of three representative clones (362-bp inserts) revealed $99.7 \%$ nucleotide identity with the respective nifH sequence of Azoarcus sp. BH72. This confirmed that nifH expression was from the inoculum. No product was obtained with RNA preparations from non- $\mathrm{N}_{2}$-fixing control plants inoculated with the nif $K^{-}$mutant, in contrast to DNA preparations where a band amplified which did not hybridize (not shown). This suggested that nifH mRNA levels in control plants were not sufficiently high to allow detection in our assay, although diazotrophic bacteria were present in the rhizosphere. Apparently, during incubation in the greenhouse, the non- $\mathrm{N}_{2}$-fixing control plants had become contaminated by bacteria other than the wild-type inoculum that did not fix $\mathrm{N}_{2}$ at the time of sampling, although they were probably able to do so. The expression of BH72 nifH in test plants, but not in control plants, confirmed that the source of plant nitrogen for

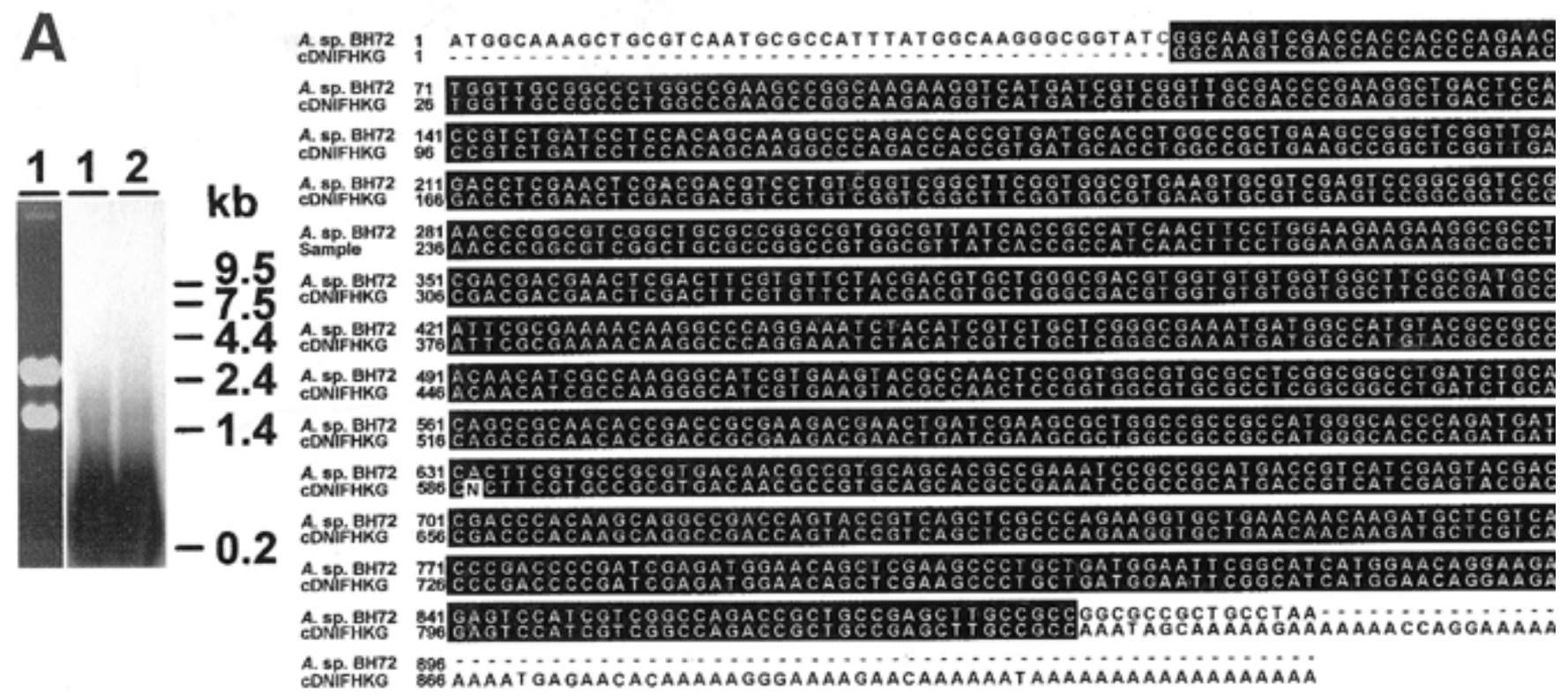

Fig. 1. Polyadenylation of Azoarcus mRNA. A, Agarose gel (left) and corresponding northern blot (right) of mRNA from Azoarcus sp. strain BH72 hybridized with a 27-base poly (dT) oligo at $54^{\circ} \mathrm{C}$. Lane 1, total mRNA; lane 2, RNA purified with oligo(dT) cellulose. B, Alignment of the nifH DNA sequence of Azoarcus sp. strain BH72 with the sequence of a cDNA clone retrieved from a library of polyadenylated RNA from roots of inoculated Kallar grass; identical nucleotides are boxed in black. 
the test plants was $\mathrm{N}_{2}$-fixation by Azoarcus sp. BH72. No nifH PCR product was obtained from shoot DNA preparations, confirming our data from $16 \mathrm{~S}$ rDNA directed PCR amplifications (data not shown).

\section{Analysis of nifH mRNA in roots of noninoculated field-grown plants.}

Studies in the natural environment are always required to evaluate laboratory experiments. In order to evaluate the role of Azoarcus sp. BH72 as a diazotroph in the environment, we collected soil cores containing Kallar grass from a waterlogged, salt-affected field in the Punjab of Pakistan which was surveyed for $\mathrm{N}_{2}$-fixing bacteria in 1984 and 1988 (ReinholdHurek et al. 1993b). Additionally, soil cores containing Oryza minuta from a lowland area at Dayap, Laguna, Philippines $\left(121^{\circ} \mathrm{E}, 15^{\circ} \mathrm{N}\right)$ were collected. Plants were grown in the original, permanently wet soil without application of nitrogenous fertilizer for several months in the phytotron, in order to deplete the nitrogen from the soil. To demonstrate that Azoarcus sp. BH72 was initially present in the rhizospheres of the samples and was not introduced later, roots were analyzed immediately after arrival using 16S rDNA-targeted, Azoarcus spp.specific PCR protocols (see above), and by classical isolation procedures. Again, attempts to isolate Azoarcus sp. BH72 failed. In $16 \mathrm{~S}$ rDNA clone libraries of Kallar grass, but not of Oryza minuta, 385-bp inserts with the identical sequence of this organism were found (not shown). This indicates that Azoarcus. sp. BH72 is a constant member of the natural microbial community associated with Kallar grass at the site of study in Pakistan.

After 3 months, Kallar grass roots were sampled and analyzed by RT-PCR for the occurrence of nifH transcripts. Amplification products were obtained from RNA (RT-PCR) as well as from DNA (PCR) preparations of Kallar grass roots (Fig. 2B). Southern analyses, using nifH probes from Azoarcus sp. BH72 and Azospira oryzae 6a3, indicated that the diversity among nifH amplicons was nonrandom (Fig. 2B). In Kallar grass, a majority of nifH transcripts and DNA amplicons were highly related to the gene from Azoarcus sp. $\mathrm{BH} 72$ and not to nifH genes typical for $\alpha$-Proteobacteria, to which the nifH probe from Azospira oryzae 6a3 is highly homologous (Hurek et al. 1997a).
As a control for the efficiency of nucleic acid extraction, cells of the Gram-positive bacterium Bacillus subtilis were added to the root samples prior to the lysis. Nucleic acids could be detected by $16 \mathrm{~S}$ rDNA-targeted PCR using specific primers (Fig. 3); thus, our method appeared to be effective for disruption of cells with different cell wall types. Therefore, our amplifications probably reflected the quantitative abundance of templates in the environmental samples.

To avoid interpreting misincorporations in early PCR cycles as template difference (Handt et al. 1996), sequences were determined from two independent RT-PCR amplifications. Six random clones were analyzed. All sequences showed $99.7 \%$ nucleotide identity to the respective nifH fragment of strain BH72. NifH and 16S rDNA sequence comparisons between closely related Azoarcus spp. (Hurek et al. 1997a; ReinholdHurek et all. 1993b) show strain level divergence or even organismal identity (Fig. 4). This shows that the environmental cDNA sequences are clearly derived from Azoarcus sp. BH72type bacteria.

\section{Estimation of nifH-mRNA abundance in roots.}

In order to estimate how large the nitrogen-fixing populations were, we quantified nifH transcription by calibrating the RT-PCR. Pure cultures of Azoarcus sp. BH72 were grown under conditions optimal for $\mathrm{N}_{2}$-fixation in an oxygen-controlled bioreactor (Hurek et al. 1987), total RNA was extracted, and serial dilutions were subjected to a most-probable-number (MPN) $(n=3)$ RT-PCR analysis. RT-PCR reactions were run in triplicates from three RNA preparations using the template concentrations mentioned in Figure 5. The numbers of positive and negative tubes that produced amplification products were scored, constituting the complete eight dilutions MPN RT-PCR data matrix. In all amplifications, products were obtained from 100 to $2,000 \mathrm{ng}$ of RNA template. No bands were obtained from 1, 10, or $50 \mathrm{ng}$ of RNA. The MPN estimate was determined to be 20.17. From dividing the undiluted RNA template by the MPN estimate, it was calculated that the RT-PCR detection limit was $99.2 \mathrm{ng}$ of RNA, corresponding to $3.3 \times 10^{7}$ cells of strain BH72. Also, the RNA extracted from roots was subjected to a MPN RT-PCR ( $n=4$, five dilutions), starting with 5 of the $25 \mu \mathrm{l}$ of RNA dissolved in diethyl pyrocarbonate(DEPC) treated water. Using the same procedures detailed



Fig. 2. Expression of nifH genes associated with roots of Kallar grass. A and B, Representative agarose gel (left) and corresponding Southern Blot (right) of polymerase chain reaction (PCR) products amplified with universal primers for $n i f H$. A and $\mathbf{B}$, Reverse transcription (RT)-PCR from RNA or B, PCR from DNA. Typical data from four RNA and DNA extractions are shown. A, Root samples taken from plants inoculated with Azoarcus sp. (2- $\mu$ lemplates) or B, from a natural site in the Punjab of Pakistan ( $0.5-\mu \mathrm{l}$ templates). Controls, A, PCR amplification of RNA extracted from roots inoculated with strain BH72 or B, field-grown plants after heat inactivation of reverse transcriptase. Positive controls: RNA from Azoarcus sp. strain BH72 or Azospira oryzae 6a3. B, Root DNA: sample taken after RNA extraction prior to DNase treatment. Hybridization of Southern blots was carried out at high stringency with digoxygeninlabeled DNA probes of nifH genes of strains $\mathrm{BH} 72$ or 6a3, respectively. 
above, the detection limit for nifH transcripts was estimated to be $1 \mu$ of template from RNA preparations of plants inoculated with the wild type, corresponding to $1 \times 10^{10}$ nitrogen fixing bacteria per gram of root dry weight. In the environmental samples (Kallar grass roots) the detection limit was two times lower and, accordingly, the level of Azoarcus. sp. BH72 nifH mRNA twice as high.

\section{Distribution of nifH-mRNA in roots of rice.}

In order to determine whether unculturability of plant-associated bacteria highly active in nitrogen fixation is a widespread phenomenon which is not only restricted to Azoarcus sp. BH72 and Kallar grass, we screened nifH cDNA and DNA clone libraries from the wild rice Oryza minuta. This plant had been surveyed for the presence of culturable nitrogen fixing bacteria before (Engelhard et al. 2000). Our screen revealed a higher diversity of $\mathrm{N}_{2}$-fixing bacteria than found with Kallar grass. MPN RT-PCR revealed that the level of nifH mRNA corresponded to $1 \times 10^{10}$ nitrogen fixing cells per gram of root dry weight. Clone libraries were constructed from the RT-PCR product and from nifH amplicons obtained from rice rot DNA. None of the eight clones picked at random harbored nifH sequences related to Azoarcus sp. BH72.

To determine the evolutionary relationships between the NifH sequences from diazotrophs associated with wild rice and those associated with Kallar grass, we performed a phylogenetic tree analysis as outlined by Hurek and associates (1997a) on NifH protein sequences from cultivated and uncultivated microorganisms (Fig. 6). This analysis identified two cDNA clones from roots of wild rice (Om13B and Om212A) as members of the $\mathrm{Kg}-2$ and $\mathrm{Kg}-3$ nifH clusters with bootstrap values of 70 and $98 \%$, respectively. Two other clones from Oryza minuta (Om16D and OmA45) are highly related to nifH sequences $15(38)$ and 15(101) retrieved from roots of modern rice in Nepal (Engelhard et al. 2000) and to H-RIC19 and HRIC14 from roots of $O$. sativa L. cv. nihonbare in Japan (Ueda et al. 1995). Numerous other nifH cDNA clones were recently retrieved from roots of other rice species which cluster with these sequences at high bootstrap values (T. Hurek, unpublished data). Since these sequences frequently occur and have been first detected in Oryza spp., we propose to call this group of entirely uncultivated microorganisms $\Omega$-cluster. The other DNA or cDNA sequences from rice clustered with nifH genes from $\alpha$-Proteobacteria, from Gram-positives, or, as in the case of OmD25, could not be assigned to other described bacteria.

\section{DISCUSSION}

There are many reports of plant growth promotion of gramineae by diazotrophic bacteria, such as Azospirillum spp. (Okon and Labandera-Gonzalez 1994), or even rhizobia (Biswas et al. 2000; Yanni et al. 1997). However, in all cases except for Acetobacter diazotrophicus and sugarcane (Sevilla et al. 2001), this growth response was not a result of the supply of biologically fixed nitrogen (Bashan and Holguin 1997; Yanni et al. 1997). Due to the following line of evidence, we have demonstrated that Azoarcus sp. BH72 can contribute significant amounts of fixed nitrogen to its host plant Kallar grass. First, after 8 months, plants inoculated with wild-type bacteria had higher dry weights, accumulated more nitrogen $(P$ $<0.05)$, and had lower $\delta^{15} \mathrm{~N}$ signatures $(P<0.005)$ than plants inoculated with a nifK $K^{-}$mutant strain. The relatively small change of initial and final nitrogen content of the potting medium and its higher $\delta^{15} \mathrm{~N}$ signature with respect to wild typetreated plants in these experiments demonstrated that wild type-treated plants must have had access to combined nitrogen from nitrogen fixation. Second, sequence identity of retrieved partial nifH transcripts with the published nifH sequence of Azoarcus sp. BH72 (Egener et al. 2001) indicated that nitrogen fixation by Azoarcus sp. BH72 and not by other adventitious diazotrophic bacteria had provided combined nitrogen to the plant. Third, the low $\delta^{15} \mathrm{~N}$ signature of shoots indicated that combined nitrogen had been transferred from bacteria to plant material, because the inoculum could be not detected in the shoot. However, it is not clear yet whether this nitrogen had been transferred directly or after decay of the bacteria.

If our data are extrapolated to an annual hectare basis, approximately $34 \mathrm{~kg}$ of $\mathrm{N} \mathrm{ha}^{-1}$ year $^{-1}$ were derived from $\mathrm{N}_{2}$-fixation, an agronomically useful value, which would amount to approximately $50 \%$ of the nitrogen required for sustaining traditional wetland rice culture (Bennet and Ladha 1992). This indicates that biological nitrogen fixation by a particular endophyte can contribute substantially to plant growth. Our estimate is more than twice the contribution of nitrogen fixation calculated for hardwood species in the northeastern United States (Bormann et al. 1980). However, it is considerably lower than the estimated input of $150 \mathrm{~kg}$ of $\mathrm{N} \mathrm{ha}^{-1}$ year $^{-1}$ by biological $\mathrm{N}_{2}$ fixation in outdoor-grown sugar cane plants (Boddey et al. 1995). Probably, low light levels at certain periods of the year in the glasshouse prevented a full development of the $\mathrm{N}_{2}$-fixation potential in the Azoarcus plant association.

In contrast to Acetobacter diazotrophicus and sugar cane, where the $\mathrm{N}_{2}$-fixing bacteria contributing nitrogen to the plant remain culturable (Sevilla et al. 2001), in Azoarcus sp. BH72 and Kallar grass they became unculturable. As had been the case in 1988 (Reinhold-Hurek et al. 1993b), an attempt to isolate Azoarcus sp. BH72 failed, due to the low abundance of culturable diazotrophic endophytes. Wild-type and mutant Azoarcus sp. BH72 could not be reisolated using established protocols (Reinhold et al. 1986; Reinhold-Hurek et al. 1993b); therefore, the only means by which Koch's postulates could be fulfilled and the $\mathrm{N}_{2}$-fixing agent be identified was by molecular taxonomy. We also intended to show that the identified $\mathrm{N}_{2-}$ fixing agent and not an adventitious microbe was highly active in nitrogen fixation; therefore, we had to make extensive use of molecular methods in microbial ecology.

Methods to obtain sequence data from microbial communities or pure cultures either include or omit a PCR amplification step. Although a routine method, PCR amplification can cause several problems, such as the retrieval of no, contaminating, or artefactual sequences (von Wintzingerode et al. 1997). The identification of polyadenylated nifH mRNA from unculturable Azoarcus sp. BH72 in roots of inoculated plants without a PCR amplification step indicated unambiguously that the inoculum was metabolically active and fixed nitrogen. Although it is established that RNA may be polyadenylated in prokaryotes as it is in eukaryotes (Cohen 1995), it is not known how widespread polyadenylation among bacteria is. Therefore, the retrieval of polyadenylated nifH mRNA is currently not a good

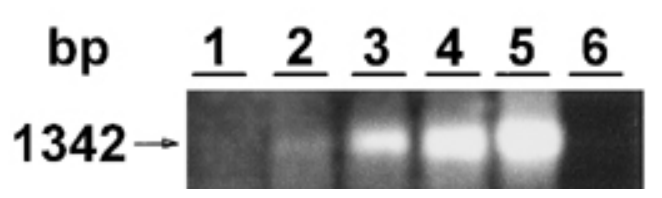

Fig 3. Control polymerase chain reaction (PCR) for lysing efficiency of RNA extraction protocol. Agarose gel of PCR products amplified using a combination of universal and taxon specific $16 \mathrm{~S}$ rDNA-targeted primers for Bacillus subtilis. Prior to RNA extraction, no (lane 1), $10^{4}$ (lane 2), $10^{6}$ (lane 3), and $10^{8}$ (lane 4) washed cells of B. subtilis were added to $400 \mathrm{mg}$ root fresh weight of Kallar grass from experiment A; the DNase step was omitted from the purification protocol, and the sample used as template for PCR. Pure control DNA of Bacillus subtilis (lane 5), no-template control (lane 6). 
method to evaluate $\mathrm{N}_{2}$ fixation of diverse microbial populations as they occur in natural environments.

For the quantitative evaluation of nifH messengers in microbiologically undefined environments, PCR amplification with the universal primers of Zehr and McReynolds (1989) proved to be the method of choice. High abundance of partial nifH transcripts from Azoarcus sp. BH72, also in environmental samples from naturally grown Kallar grass in the Punjab of Pakistan, confirmed the important role of this bacterium in biological $\mathrm{N}_{2}$ fixation with this plant in the natural environment. The phylogenetic analysis of the retrieved $\mathrm{NifH}$ sequences which we obtained agreed in all major clades with a previous study on the same coding region (Zehr et al. 1998). None of these sequences are represented by cultivated bacteria. Except for one sequence which clusters with Azoarcus NifH phylotypes (Hurek et al. 1997a) and for sequences belonging to the $\Omega$-cluster, none of the sequences detected in a previous study on a modern line of rice (Ueda et al. 1995) were found in Kallar grass or wild rice. This result contrasts with those of a previous study in which $\mathrm{N}_{2}$-fixing bacteria from most major groups were found associated with a modern line of rice (Ueda et al. 1995). The nifH primer set was shown to be unbiased to different types of templates (Zehr and Capone 1996); therefore, it is unlikely that these results are artifacts of amplification efficiencies for DNA or cDNA templates caused by the universal nifH-targeted primers (von Wintzingerode et al. 1997). This also is supported by retrieval of nifH sequences from all major clades in a previous study (Engelhard et al. 2000). Therefore, our amplifications probably reflected the quantitative abundance of templates in the environmental samples, a prerequisite for interpreting the community structure or function of microbiota in their natural environment (von Wintzingerode et al. 1997).

Quantitative evaluation of nifH transcription in the inoculation experiment and in environmental samples indicated a high potential for plant-associated $\mathrm{N}_{2}$ fixation in Azoarcus sp. $\mathrm{BH} 72$. The amount of nifH transcript per gram of root dry weight was found to be equivalent to that produced by 1 to $2 \times$ $10^{10} \mathrm{~N}_{2}$-fixing cells of strain BH72 in pure culture. However, the actual numbers of $\mathrm{BH} 72$ cells per gram of root dry weight

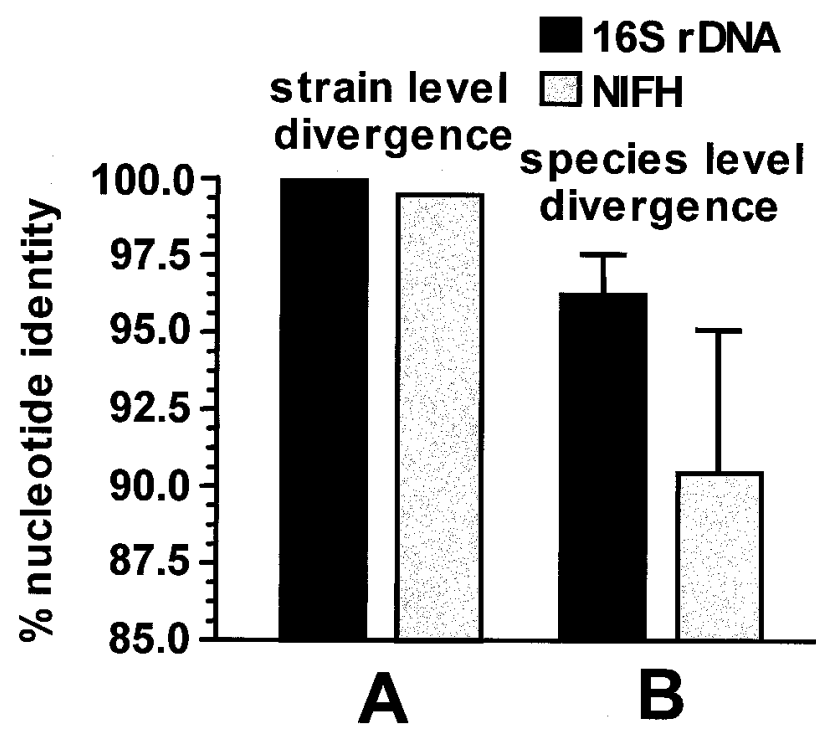

Fig. 4. 16S rDNA and nifH gene divergence in Azoarcus spp. A, Sequence comparisons of Azoarcus communis strains SWuB3 and S2. B, Sequence comparisons of the different species Azoarcus. sp. strain BH72, A. indigens $\mathrm{VB} 32$, and $A$. communis SWuB3. NifH sequences were $\mathbf{A}, 330$ or B, 327 bases long. For 16S rDNA, almost full-length sequences were compared. were probably much lower than 1 to $2 \times 10^{10}$ because there is evidence from nifH::gusA expression in roots of rice by strain $\mathrm{BH} 72$ that the nifH expression level of bacteria inside the root can be more than a magnitude higher than in pure cultures(Egener et al. 1999; S. Wiese and B. Reinhold-Hurek, unpublished data). Nonetheless, considering that a root of Kallar grass with a length of $1 \mathrm{~cm}$ has approximately a dry weight of $0.3 \mathrm{mg}$ and assuming that 30 bacteria would be present in the cortex per millimeter, Kallar grass could accommodate $1 \times 10^{9}$ bacteria per gram of root dry weight. Apparently no specialized, visible plant structures are required to accommodate the $\mathrm{N}_{2}$-fixing agents, as in the rhizobium-legume symbiosis. A complex template mixture as used here might reduce the efficiency of specific amplification; therefore, these values are under- rather than overestimates. Environmental conditions that allow high nitrogenase activity also favor high levels of nifH expression in Azoarcus sp. BH72 (Egener et al. 1998, 1999). Abundant expression and function of nifH in the rhizosphere of inoculated and field-grown plants are consistent with an important role of Azoarcus sp. BH72 in biological $\mathrm{N}_{2}$ fixation in the natural environment. Previous data on nifH expression of Azoarcus sp. BH72 in roots of field-grown Kallar grass plants were confirmed, which showed in situ hybridization with antisense nifH probes (Hurek et al. 1997a).

Our findings require a fundamental reconsideration of the ecology of $\mathrm{N}_{2}$-fixing grass endophytes. The predominance and abundance of culturable diazotrophic endophytes in this habitat is believed to reflect the extent to which they contribute nitrogen to the plant. In contrast, we have shown here that a grass-endophytic-bacterium association functions in $\mathrm{N}_{2}$-fixation with its host plant through the establishment of a nonculturable state, at least to our current knowledge of cultivation techniques. By maintaining an active metabolism, nonculturable Azoarcus sp. BH72 provided fixed nitrogen to the plant and contributed to plant growth, a characteristic, that this bacterium shares with many endosymbiotic microorganisms which also are not culturable, although metabolically active (Douglas 1995). Our data on the pattern of nifH expression and on the wide occurrence of culturable Azoarcus spp. in soils and in wild and modern lines of rice (Engelhard et al. 2000) suggests that only $\mathrm{BH} 72$ and the unculturable forms play a major role in $\mathrm{N}_{2}$-fixation: known cultured $\mathrm{N}_{2}$-fixing bacteria, in contrast to uncultured diazotrophs, were neither abundant nor very active, confirming observations from Ueda and coworkers (Ueda et al. 1995). Therefore, the overwhelming majority of $\mathrm{N}_{2}$-fixing bacteria, which have been cultivated from associations with members of the Gramineae family, probably do not provide a large proportion of vascular plant nitrogen, confirming results obtained from inoculation experiments with various $\mathrm{N}_{2}$-fixing bacteria (Bashan and Holguin 1997; Giller and Day 1985). Also, the small contribution of combined nitrogen to sugar cane by Acetobacter diazotrophicus estimated from inoculation experiments (Sevilla et al. 2001) cannot explain the huge contribution of $\mathrm{N}_{2}$ fixation (Boddey et al. 1995; Urquiaga et al. 1992) observed in certain uninoculated, field-grown sugar cane cultivars. Furthermore, plant endophytes which are known to be taxonomically highly related can be very diverse in their genetic and biochemical capacities (Stierle et al. 1993; Young and Haukka 1996). It is therefore likely that endophytic bacteria, which respond to enumeration through classical culture procedures, are functionally different from microorganisms which usually maintain no free-living populations and only occasionally become culturable (e.g., Azoarcus sp. BH72) or are obligate endophytes. For Azoarcus sp. BH72, the interaction with rhizosphere fungi may be especially important for the maintenance of free-living populations of this bacterial species in the natural environ- 
ment. $\mathrm{N}_{2}$-fixing cells respond to coculture with an ascomycete from roots of Kallar grass with induction of complex intracytoplasmatic membranes (diazosomes) (Hurek et al. 1995) as a result of differential gene expression (Hurek et al. 1995; Karg and Reinhold-Hurek 1996). Microscopical appearance of morphologically changed strain $\mathrm{BH} 72$ suggested that complete binary fission might be inhibited and bacteria thus be arrested in growth (Hurek et al. 1995). Probably in nature, the formation of diazosomes would restrict differentiated bacteria in their ability to compete with other organisms, leading to physiologically active but unculturable Azoarcus cells. Therefore, the survival of the population may critically depend on the strict control of the differentiation process, still maintaining a sufficiently high number of viable, culturable cells. Otherwise, the ecological advantage of such an event for these bacteria would be hard to understand, because differentiations of populations would threaten this genotype by extinction. Thus, either this morphological change is a "dead end" in a fairly exclusive environment, analogous to the differentiation of rhizobia to bacteroids in nodule tissue of the Rhizobium-legume symbiosis, or it is an intermediate stage of an as yet undiscovered phenomenon. Future research should focus on unculturable $\mathrm{N}_{2}$ fixing grass endophytes because they apparently play an important role in plant ecology that has been neglected.

\section{MATERIALS AND METHODS}

\section{Plant growth and analysis.}

Seedlings from surface-sterilized seeds of Kallar grass, which are generally too small to survive immediate growth under $\mathrm{N}$-free conditions, were grown in a glasshouse in garden soil fertilized twice per week with Long Ashton nutrient solution (Hewitt 1996). Two-month-old plants $(2.0 \pm 0.3 \mathrm{~g}$ fresh weight) were transplanted into free draining compartments (Wyss et al. 1991), each containing $50 \mathrm{~g}$ of a mixture comprising sterile vermiculite (20\% wt/wt), silica 70/25 (20\% wt/wt), montmorillonite $(20 \% \mathrm{wt} / \mathrm{wt})$, and quartz sand $(40 \% \mathrm{wt} / \mathrm{wt})$. The potting medium of each compartment was inoculated with either $10^{8}$ cells of Azoarcus sp. BH72 or the isogenic nifK $K^{-}$mutant strain BHNKD4 (Hurek et al. 1995). Plants were grown for up to 8 months and fertilized once a week with $20 \mathrm{ml}$ of a quarter-strength combined nitrogen-free Long Ashton nutrient solution containing orthophosphate $\mathrm{P}$ at $10 \mathrm{mg}$ liter $^{-1}$. $\mathrm{Ca}\left(\mathrm{NO}_{3}\right)_{2} \cdot 4 \mathrm{H}_{2} \mathrm{O}$ was replaced by $\mathrm{CaCl}_{2}$. Dry weights were measured on freeze-dried plants.

Total nitrogen contents of the potting medium were measured using an elemental analyzer (NC 2100 Soil Analyzer, CE Instruments). $\delta^{15} \mathrm{~N}$ values of all samples were measured using a Europa Scientific Roboprep elemental analyzer coupled to a Europa Tracermass (Handley et al. 1993) and were calculated as $\left.\left.\delta^{15} \mathrm{~N}=\left[\left(\mathrm{R}_{\text {(sample) }}-\mathrm{R}_{\text {(standard) }}\right)\right] / \mathrm{R}_{\text {(standard) }}\right)\right] \times 10^{3}$, where $\mathrm{R}$ is the ratio ${ }^{15} \mathrm{~N} /{ }^{14} \mathrm{~N}$ and the universally accepted standard is atmospheric $\mathrm{N}_{2}$.

\section{$\delta^{15} \mathrm{~N}$ of bacterial strain $\mathrm{BH} 72$.}

In order to estimate the $\delta^{15} \mathrm{~N}$ of strain $\mathrm{BH} 72$, bacteria were grown in nitrogen-free medium in 1-liter rubber stoppered Erlenmeyer flasks with an initial oxygen partial pressure of 1.5 to $2.0 \%$ or in a fermentor at $2 \mu \mathrm{M}$ dissolved $\mathrm{O}_{2}$ according to standard conditions. Cultures were harvested at an optical density $>100$ times initial. No significant amounts of combined nitrogen were detected in the culture filtrate. The $\delta^{15} \mathrm{~N}$ of nitrogen (tank) gas introduced to the systems was $1.43 \%$.

\section{RNA and DNA extraction.}

Crude total RNA was isolated using a modification of the pine tree method (Chang et al. 1993) which increased the effi- ciency of nucleic acids recovery. Briefly, ground, tapwaterwashed tissue (400 $\mathrm{mg}$ of root fresh weight equivalent to 80 mg dry weight) was homogenized with a tube pestle in extraction buffer. Debris was spun down, washed three times in TE buffer (10 mM TrisHCl, pH 8.0, 1 mM NaEDTA), incubated for $20 \mathrm{~min}$ at $37^{\circ} \mathrm{C}$ in $25 \%$ polyethylene glycol with lysozyme at $1 \mathrm{mg} / \mathrm{ml}$, and spun down again. The supernatant from the first centrifugation was recovered. The pellet was incubated for $10 \mathrm{~min}$ at $37^{\circ} \mathrm{C}$ in $1 \mathrm{ml}$ of lysing solution $(0.5 \%$ sodium dodecyl sulfate and Proteinase K [Merck, Darmstadt, Germany] at $0.1 \mathrm{mg} / \mathrm{ml}$ in TE buffer). Extraction buffer from the first centrifugation was added and samples were incubated at $65^{\circ} \mathrm{C}$ for 15 min. For extraction of RNA from Azoarcus sp. $\mathrm{BH} 72$, cells were incubated in lysing solution before extraction buffer was added. For RT-PCR amplification, aliquots of RNA preparations were treated at $37^{\circ} \mathrm{C}$ for 20 min with $30 \mathrm{U}$ RNAse-free DNAse I (Boehringer Mannheim, Mannheim, Germany) in $50 \mu$ l of DNAse I buffer ( $20 \mathrm{mM}$ MES pH 7.2, 5 $\mathrm{mM} \mathrm{MgCl} 2,5 \mathrm{mM} \mathrm{CaCl} 2$ ) and resuspended in $25 \mu \mathrm{l}$ of DEPCtreated water. The quantity of total RNA was too small to be determined accurately by UV absorption. DNA samples were taken from the same samples previous to DNAse treatment.

\section{DNA and RNA analyses.}

DNA and RNA techniques such as Southern and Northern blotting (Reinhold-Hurek et al. 1993a), hybridization, cloning, and sequence analysis followed standard protocols (Ausubel et al. 1987). Sequence analysis using an automated sequencer (ALFexpress, AmershamPharmacia Biotech) and general 16S rDNA-targeted PCR (Hurek et al. 1997b) and Azoarcus-specific 16S rDNA-targeted PCR (Hurek and Reinhold-Hurek 1995) were carried out as previously described. PCR products were cloned into the vector pUC19 (Yanisch-Perron et al. 1985).

RT-PCR was done with Ready-to-Go RT-PCR beads following the manufacturer's specifications (Amersham Pharmacia Biotech, Freiburg, Germany). Reverse transcription was carried out with NIFHR-580 (5'-GTT(AG)(CT)A(AGT)AT(AGC)A(GT)(AGC)CC(AGC)CC(AGC)AG-3'), a universal reverse primer for the nitrogenase $\mathrm{Fe}$ protein gene. For amplification of cDNA products, universal primers (Zehr and McReynolds 1989) were used. Amplification consisted of 40 cycles at $94^{\circ} \mathrm{C}$ for $1 \mathrm{~min}, 57^{\circ} \mathrm{C}$ for $2 \mathrm{~min}$, and $72^{\circ} \mathrm{C}$ for $2 \mathrm{~min}$ in 0.2-ml thin-walled tubes and a Techne Progene cycler (Techne, Duxford, UK). For amplification of DNA templates, primers and PCR conditions were identical and the reverse transcriptase was heat-inactivated by incubation of the reaction mixture for $10 \mathrm{~min}$ at $95^{\circ} \mathrm{C}$ before the template was added.

Polyadenylated RNA was purified from total RNA preparations by chromatography on oligo(dT) cellulose. cDNA synthesis and cloning of double stranded cDNA into expression vector lambda ZAP was done with a ZAP-cDNA synthesis kit (Stratagene, San Diego, CA), following standard procedures.

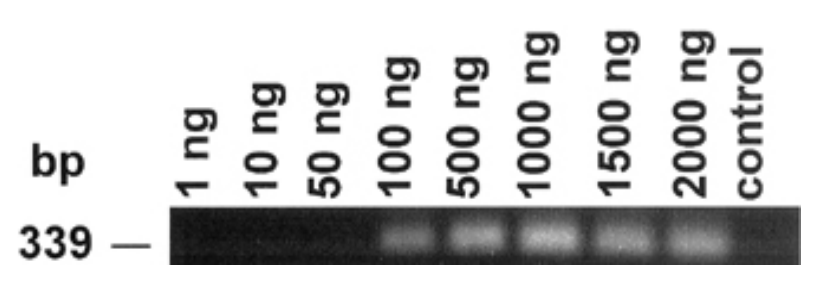

Fig. 5. Calibration of nifH mRNA expression by reverse transcription-polymerase chain reaction (RT-PCR). RNA preparations from nitrogen-fixing cells of Azoarcus sp. BH72 grown in a fermentor at $2 \mu \mathrm{M}$ dissolved $\mathrm{O}_{2}$ were diluted and used as templates. Control: reverse transcriptase was heat inactivated prior to PCR. Agarose gel of PCR products. Typical data from three RNA extractions are shown. 


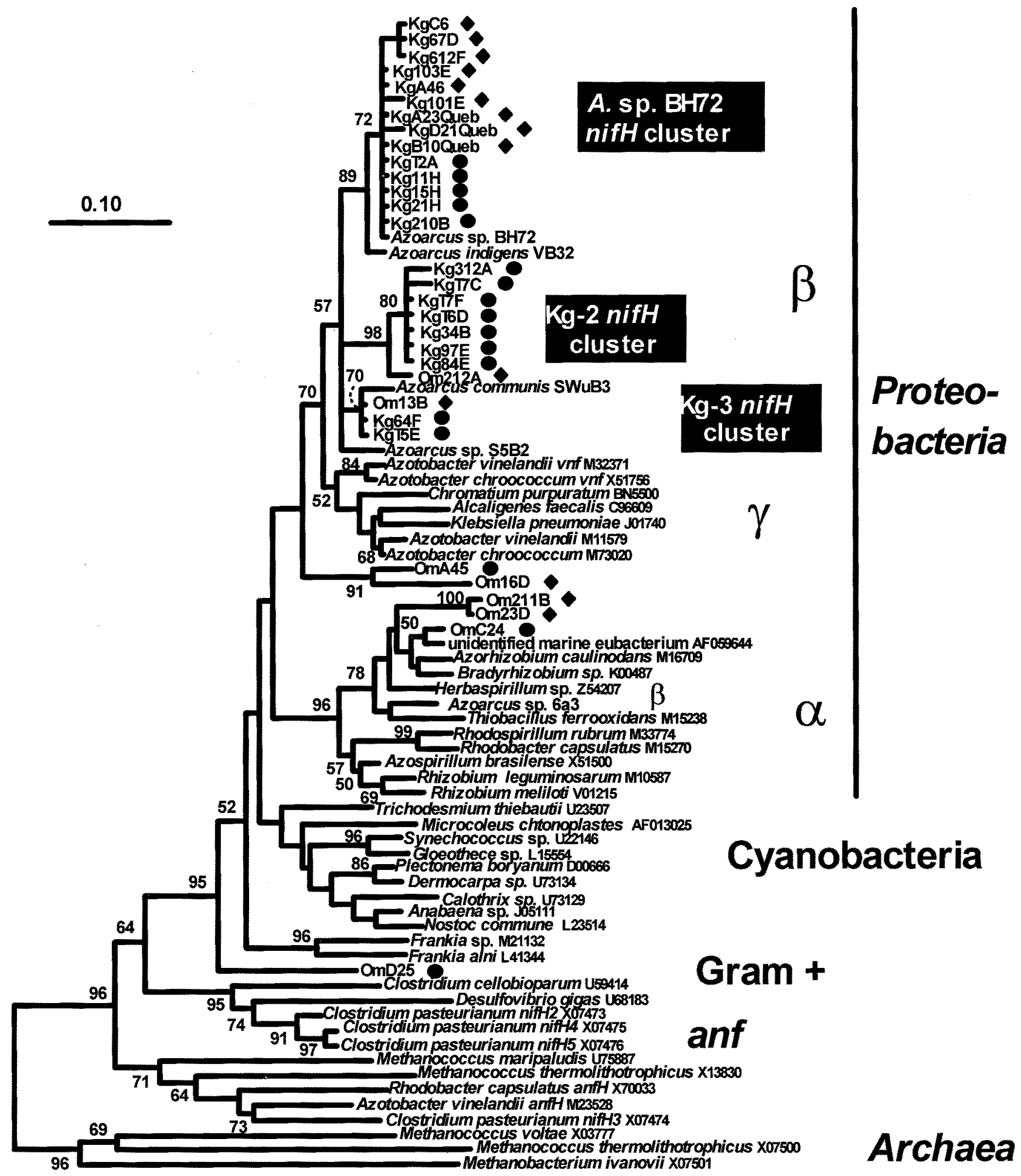

Fig. 6. Phylogenetic analysis of nifH DNAs and nifH mRNAs detected in the rhizospheres of Kallar grass and Oryzae minuta. Identical sequences were omitted in the phylogenetic analysis, but were included in the figure. Tree inference on comparisons of amino acids (122 sites) was done using a neighborjoining algorithm and a Poisson correction distance matrix as described elsewhere (Hurek et al. 1997a). Horizontal branch lengths are drawn to scale with the bar indicating 0.1 replacements per site. Bootstrap confidence levels are shown as the percentage of 100 replications at the nodes, when greater than $50 \%$. Accession numbers are given for reference sequences retrieved from databases. $\alpha, \beta$, and $\gamma$ represent the positions of different subclasses of the Proteobacteria; $\bullet=$ DNA clones and $\bullet=$ cDNA clones. Clone designation: retrieved from Kallar grass, field grown (Kg); Kallar grass, inoculated with Azoarcus sp. BH72 (KgQueb); or O. minuta (Om). 
For analysis of lysing efficiency for nucleic acid extraction, Bacillus subtilis cells were added to the sample. 16S rDNA from crude RNA preparations was first amplified with PCR primers 25f (5'-AACTGTAAGAGTTTGATCCTGGCTC-3') and 1492r (5'-TACGGCTTACCTTGTTACGACTT-3'), followed by a second amplification where the primer $25 \mathrm{f}$ was replaced by BS185 (5'-TGGTTGTTTGAACCGCATGG-3'), and 40 cycles. PCR primer BS185 is specific for Bacillus subtilis, and targets Escherichia coli position 185 in the $16 \mathrm{~S}$ rDNA corresponding to the $3^{\prime}$ end of the primer.

MPN calculations were made using the MPNSolve program from Stephan Schneider, Department of Anthropology and Ecology at the University of Geneva, Switzerland.

\section{ACKNOWLEDGMENTS}

We thank H. Vierheilig for help with setting up of the plant experiment, and R. Brumme (Institute of Soil Science and Forest Nutrition, Göttingen, FRG) for ${ }^{15} \mathrm{~N}$ analysis of soil nitrogen. T. Hurek was supported by scholarships from the government of Québec, Canada and the Max-Planck society in Germany. Scottish Crop Research Institute is grant-aided by the Scottish Office Agriculture, Environment and Fisheries Department. Rice sampling was supported by a grant from BMZ/GTZ to B. Reinhold-Hurek in cooperation with J. K. Ladha, IRRI, Philippines, and a BMBF grant also supported parts of the project.

\section{LITERATURE CITED}

Ausubel, F. M., Brent, R., Kingston, R. E., Moore, D. D., Seidman, J. G., Smith, J. A., and Struhl, K., eds. 1987. Current Protocols in Molecular Biology. John Wiley \& Sons, New York.

Bashan, Y., and Holguin, G. 1997. Azospirillum-plant relationships: Environmental and physiological advances (1990-1996). Can. J. Microbiol. 43:103-121.

Bennet, J., and Ladha, J. K. 1992. Introduction: Feasibility of nodulation and nitrogen fixation in rice. Pages 1-14 in: Nodulation and Nitrogen Fixation in Rice. G. S. Kush and J. Bennet, eds. International Rice Research Institute, Manila, Philippines.

Biswas, J. C., Ladha, J. K., Dazzo, F. B., Yanni, Y. G., and Rolfe, B. G. 2000. Rhizobial inoculation influences seedling vigor and yield of rice. Agron. J. 92:880-886.

Boddey, R. M. 1995. Biological nitrogen fixation in sugar cane: A key to energetically viable biofuel production. Crit. Rev. Plant Sci. 14:263279.

Boddey, R. M., De Oliveira, O. C., Urquiaga, S., Reis, V. M., De Olivares, F. L., Baldani, V. L. D., and Doebereiner, J. 1995. Biological nitrogen fixation associated with sugar cane and rice: contributions and prospects for improvement. Plant Soil 174:195-209.

Bormann, F. H., Likens, G. E., and Melillo, J. M. 1980. Nitrogen budget for an aggrading northern hardwood forest ecosystem. Science 196:981-983.

Chang, S., Puryear, J., and Cairney, J. 1993. A simple and efficient method for isolating RNA from pine trees. Plant Mol. Biol. Rep. 11:113-116.

Cohen, S. N. 1995. Surprises at the $3^{\prime}$ end of prokaryotic RNA. Cell 80:829-832.

Douglas, A. E. 1995. The ecology of symbiotic microorganisms. Adv. Ecol. Res. 26:69-103.

Egener, T., Hurek, T., and Reinhold-Hurek, B. 1998. Use of green fluorescent protein to detect expression of nif genes of Azoarcus sp. BH72, a grass-associated diazotroph, on rice roots. Mol. Plant-Microbe Interact. 11:71-75.

Egener, T., Hurek, T., and Reinhold-Hurek, B. 1999. Endophytic expression of nif genes of Azoarcus sp. strain BH72 in rice roots. Mol. PlantMicrobe Interact. 12:813-819.

Egener, T., Martin, D. E., Sarkar, A., and Reinhold-Hurek, B. 2001. Role of a ferrodoxine gene cotranscribed with the nifHDK operon in $\mathrm{N}_{2}$ fixation and nitrogenase "switch off" of Azoarcus sp. strain BH72. J. Bacteriol. 183:3752-3760.

Engelhard, M., Hurek, T., and Reinhold-Hurek, B. 2000. Preferential occurrence of diazotrophic endophytes, Azoarcus spp., in wild rice species and land races of Oryza sativa in comparison with modern races. Environ. Microbiol. 2:131-141.

Giller, K. E., and Day, J. M. 1985. Nitrogen fixation in the rhizosphere: significance in natural and agricultural systems. Pages 127-147 in: Ecological Interactions in Soil. A. H. Fitter, D. Atkinson, D. J. Read, and M. Busher, eds. Blackwell Scientific Publications, Oxford.
Handley, L. L., Daft, M. J., Wilson, J., Scrimgeour, C. M., Ingleby, K., and Sattar, M. A. 1993. Effects of the ecto- and VA-mycorrhizal fungi Hydnangnium carneum and Glomus clarum on the delta nitrogen-15 and delta carbon-13 values of Eucalyptus globulus and Ricinus communis. Plant Cell Environ. 16:375-382.

Handt, O., Krings, M., Ward, R. H., and Pääbo, S. 1996. The retrieval of ancient human DNA sequences. Am. J. Hum. Gen. 59:368-376.

Hewitt, J. E. 1966. Sand and water culture methods used in the study of plant nutrition. 2nd ed. Commonwealth Agricultural Bureaux, Famham Royal Bucks, U.K.

Hoering, T. C., and Ford, H. T. 1960. The isotope effect in the fixation of Azotobacter. J. Am. Chem. Soc. 82:376-378.

Hurek, T., Burggraf, S., Woese, C. R., and Reinhold-Hurek, B. 1993. 16S rRNA-targeted polymerase chain reaction and oligonucleotide hybridization to screen for Azoarcus spp., grass-associated diazotrophs. Appl. Environ. Microbiol. 59:3816-3824.

Hurek, T., Egener, T., and Reinhold-Hurek, B. 1997a. Divergence in nitrogenases of Azoarcus spp., Proteobacteria of the $\beta$-subclass. J. Bacteriol. 179:4172-4178.

Hurek, T., Reinhold, B., Fendrik, I., and Niemann, E. G. 1987. Root-zonespecific oxygen tolerance of Azospirillum spp. and diazotrophic rods closely associated with Kallar grass. Appl. Environ. Microbiol. 53:163169.

Hurek, T., and Reinhold-Hurek, B. 1995. Identification of grass-associated and toluene-degrading diazotrophs, Azoarcus spp., by analyses of partial 16S ribosomal DNA sequences. Appl. Environ. Microbiol. 61:22572261

Hurek, T., Reinhold-Hurek, B., Van Montagu, M., and Kellenberger, E. 1994. Root colonization and systemic spreading of Azoarcus sp. strain BH72 in grasses. J. Bacteriol. 176:1913-1923.

Hurek, T., Van Montagu, M., Kellenberger, E., and Reinhold-Hurek, B. 1995. Induction of complex intracytoplasmic membranes related to nitrogen fixation in Azoarcus sp. BH72. Mol. Microbiol. 18:225-236.

Hurek, T., Wagner, B., and Reinhold-Hurek, B. 1997b. Identification of $\mathrm{N}_{2}$-fixing plant- and fungus-associated Azoarcus species by PCR-based genomic fingerprints. Appl. Environ. Microbiol. 63:4331-4339.

James, E. K., and Olivares, F. L. 1998. Infection and colonization of sugar cane and other graminaceous plants by endophytic diazotrophs. Crit. Rev. Plant Sci. 17:77-119.

Johnson, M. D., Popowski, J., Cao, G. J., Shen, P., and Sarkar, N. 1998. Bacteriophage T7 mRNA is polyadenylated. Mol. Microbiol. 27:23-30.

Karg, T., and Reinhold-Hurek, B. 1996. Global changes in protein composition of $\mathrm{N}_{2}$-fixing Azoarcus sp. strain $\mathrm{BH} 72$ upon diazosome formation. J. Bacteriol. 178:5748-5754.

Kowalchuk, G. A., Naoumenko, Z. S., Derikx, P. J. L., Felske, A., Stephen, J. R., and Arkhipchenko, I. A. 1999. Molecular analysis of ammonia-oxidizing bacteria of the beta subdivision of the class Proteobacteria in compost and composted materials. Appl. Environ. Microbiol. 65:396-403.

Lisitsky, I., Klaff, P., and Schuster, G. 1996. Addition of destabilizing poly (A)-rich sequences to endonuclease cleavage sites during the degradation of chloroplast mRNA. Proc. Natl. Acad. Sci. USA 93:1339813403.

Lovell, C. R., Piceno, Y. M., Quattro, J. M., and Bagwell, C. E. 2000. Molecular analysis of diazotroph diversity in the rhizosphere of smooth cordgrass, Spartina alterniflora. Appl. Environ. Microbiol. 66:38143822

Merrick, M., and Edwards, R. 1995. Nitrogen control in bacteria. Microbiol. Rev. 59:604-622.

Noda, S., Ohkuma, M., Usami, R., Horikoshi, K., and Kudo, T. 1999. Culture-independent characterization of a gene responsible for nitrogen fixation in the symbiotic microbial community in the gut of the termite Neotermes koshunensis. Appl. Environ. Microbiol. 65:4935-4942.

Ohkuma, M., and Kudo, T. 1996. Phylogenetic diversity of the intestinal bacterial community in the termite Reticulitermes speratus. Appl. Environ. Microbiol. 62:461-468.

Okon, Y., and Labandera-Gonzalez, C. A. 1994. Agronomic applications of Azospirillum - an evaluation of 20 years worldwide field inoculation. Soil Biol. Biochem. 26:1591-1601.

Pace, N. R. 1997. A molecular view of the microbial diversity and the biosphere. Science 276:734-740.

Reinhold, B., Hurek, T., Niemann, E.-G., and Fendrik, I. 1986. Close association of Azospirillum and diazotrophic rods with different root zones of Kallar grass. Appl. Environ. Microbiol. 52:520-526.

Reinhold-Hurek, B., and Hurek, T. 1998. Life in grasses: diazotrophic endophytes. Trends Microbiol. 6:139-144.

Reinhold-Hurek, B., Hurek, T., Claeyssens, M., and Van, M. M. 1993a. Cloning, expression in Escherichia coli, and characterization of cellulolytic enzymes of Azoarcus sp., a root-invading diazotroph. J. 
Bacteriol. 175:7056-7065.

Reinhold-Hurek, B., Hurek, T., Gillis, M., Hoste, B., Vancanneyt, M., Kersters, K., and De Ley, J. 1993b. Azoarcus gen. nov., nitrogen-fixing proteobacteria associated with roots of Kallar grass (Leptochloa fusca (L.) Kunth) and description of two species Azoarcus indigens sp. nov. and Azoarcus communis sp. nov. Int. J. Syst. Bacteriol. 43:574-584.

Rowell, P., James, W., Smith, W. L., Handley, L., and Scimgeour, C. M. 1998. ${ }^{15} \mathrm{~N}$ discrimination in molybdenum- and vanadium-grown $\mathrm{N}_{2}$-fixing Anabaena variabilis and Azotobacter vinelandii. Soil Biol. Biochem. 30:2177-2180.

Sevilla, M., Burris, R. H., Gunapala, N., and Kennedy, C. 2001. Comparison of benefit to sugarcane plant growth and ${ }^{15} \mathrm{~N}_{2}$ incorporation following inoculation of sterile plants with Acetobacter diazotrophicus wildtype and nif mutant strains. Mol. Plant-Microbe Interact. 14:358-366.

Shrestha, R. K., and Ladha, J. K. 1996. Genotypic variation in promotion of rice dinitrogen fixation as determined by nitrogen-15 dilution. Soil Sci. Soc. Am. J. 60:1815-1821.

Stierle, A., Strobel, G., and Stierle, D. 1993. Taxol and taxane production by Taxomyces andreanae, an endophytic fungus of Pacific yew. Science 260:214-216.

Ueda, T., Suga, Y., Yahiro, N., and Matsuguchi, T. 1995. Remarkable $\mathrm{N}_{2-}$ fixing bacterial diversity detected in rice roots by molecular evolutionary analysis of $n i f H$ gene sequences. J. Bacteriol. 177:1414-1417.

Urquiaga, S., Cruz, K. H. S., and Boddey, R. M. 1992. Contribution of nitrogen fixation to sugar cane: nitrogen-15 and nitrogen balance estimates. Soil Sci. Soc. Am. J. 56:105-114.

van Berkum, P., and Bohlool, B. B. 1980. Evaluation of nitrogen fixation by bacteria in association with roots of tropical grasses. Microbiol. Rev. 44:491-517.

von Wintzingerode, F., Göbel, U. B., and Stackebrandt, E. 1997. Determi- nation of microbial diversity in environmental samples: pitfalls of PCR based rRNA analysis. FEMS Microbiol. Rev. 21:213-229.

Wyss, P., Boller, T., and Wiemken, A. 1991. Phytoalexin response is elicited by a pathogen Rhizoctonia solani but not by a mycorrhizal fungus Glomus mosseae in soybean roots. Experientia 47:395-399.

Yanisch-Perron, C., Vieira, J., and Messing, J. 1985. Improved M13 phage cloning vectors and host strains: nucleotide sequences of the M13mp18 and pUC19 vectors. Gene 33:103-119.

Yanni, Y. G., Rizk, R. Y., Corich, V., Squartini, A., Ninke, K., PhilipHollingsworth, S., Orgambide, G., De Bruijn, F., Stoltzfus, J., Buckley, D., Schmidt, T. M., Mateos, P. F., Ladha, J. K., and Dazzo, F. B. 1997. Natural endophytic association between Rhizobium leguminosarum bv. trifolii and rice roots and assessment of its potential to promote rice growth. Plant Soil 194:99-114.

Young, J. P. W., and Haukka, K. E. 1996. Diversity and phylogeny of rhizobia. New Phytol. 133:87-94.

Zani, S., Mellon, M. T., Collier, J. L., and Zehr, J. P. 2000. Expression of nifH genes in natural microbial assemblages in Lake George, New York, detected by reverse transcriptase PCR. Appl. Environ. Microbiol. 66:3119-3124.

Zehr, J. P., and Capone, D. G. 1996. Problems and promises of assaying the genetic potential for nitrogen fixation in the marine environment Microb. Ecol. 32:263-281

Zehr, J. P., and McReynolds, L. A. 1989. Use of degenerate oligonucleotides for amplification of the nifH gene from the marine cyanobacterium Trichodesmium thiebautii. Appl. Environ. Microbiol. 55:2522 2526

Zehr, J. P., Mellon, M. T., and Zani, S. 1998. New nitrogen-fixing microorganisms detected in oligotrophic oceans by amplification of nitrogenase (nifH) genes. Appl. Environ. Microbiol. 64:3444-3450. 